\title{
Collaborative learning in the production of diagnostic imaging: detailing group practices
}

\author{
Aprendizagem colaborativa na produção do diagnóstico por \\ imagem: detalhando práticas de grupos
}

\author{
Patrícia Fernanda Dorow ${ }^{1}$ (D), Gregório Varvakis ${ }^{1}$ (D), Dorzeli Salete Trzeciak ${ }^{2}$ (D), \\ Luiz Felipe Nobre de Souza ${ }^{1}$ (D) \\ ${ }^{1}$ Universidade Federal de Santa Catarina - UFSC, Programa de Engenharia e Gestão do Conhecimento, \\ Florianópolis, SC, Brasil. E-mail: patrciadorow@gmail.com; g.varvakis@ufsc.br \\ ${ }^{2}$ Instituto Euvaldo Lodi de Santa Catarina - IEL/SC, Florianópolis, SC, Brasil.
}

How to cite: Dorow, P. F., Varvakis, G., Trzeciak, D. S., Souza, L. F. N. (2020). Collaborative learning in the production of diagnostic imaging: detailing group practices. Gestão \& Produção, 27(3), e4456. https://doi.org/10.1590/0104-530X4456-20

\begin{abstract}
Considering collaborative work is a growing phenomenon, understand how groups learn effectively is critical. This research aimed to identify and detailed the practices performed in the processes of diagnostic imaging that support continuous learning in groups of radiologists. It is a multiple case study that presents practical and context dependent knowledge about group practices in the specific radiology and imaging environment. Data were collected through semi-structured observations and interviews, with members of three groups belonging to different radiology and diagnostic imaging organizations. The results of this study show how a learning culture, integration and cooperation, an adequate physical environment, the support of the leadership and the technological support when combining attendance-based and virtual activities guarantee the organizational learning in the groups and individual of the radiologist, creating transformative and disruptive paths. It concludes the use of appropriate practices facilitates the learning of the groups.
\end{abstract}

Keywords: Sharing knowledge; Group learning; Group practices; Radiology; Imaging diagnosis; Radiation protection.

Resumo: Considerando que o trabalho colaborativo é um fenômeno crescente, entender como os grupos aprendem de forma eficaz é algo crítico. Essa pesquisa teve como objetivo identificar e detalhar as práticas realizadas nos processos de produção do diagnóstico por imagem, que suportam a aprendizagem contínua em grupos de radiologistas. É um estudo de múltiplos casos, que reúne conhecimento prático e dependente do contexto sobre as práticas de grupos, no ambiente específico da radiologia e diagnóstico por imagem. Os dados foram coletados por meio de observações e entrevistas semiestruturadas, com membros de três grupos pertencentes a diferentes organizações de radiologia $e$ diagnóstico por imagem. Os resultados desse estudo evidenciam como uma cultura de aprendizado, a integração e a cooperação, um ambiente físico adequado, o apoio da liderança e o suporte tecnológico quando combinados em atividades presenciais e virtuais, garantem o aprendizado organizacional nos grupos e individual do radiologista, criando caminhos transformadores e disruptivos. Conclui-se que, o uso de práticas adequadas facilita o aprendizado dos grupos, o que ajuda a diminuir erros diagnósticos e contribui para a qualidade diagnóstica e proteção radiológica do paciente.

Palavras-chave: Compartilhamento do conhecimento; Aprendizagem; Práticas em grupo; Radiologia; Diagnóstico por imagem; Proteção radiológica.

Received Nov. 14, 2017 - Accepted Nov. 2, 2018

Financial support: There was financial support for this research from the Federal Institute of Santa Catarina - 23756.

This is an Open Access article distributed under the terms of the Creative Commons Attribution License, which permits unrestricted use, distribution, and reproduction in any medium, provided the original work is properly cited. 


\section{Introduction}

Organizational learning generally involves the analysis of adaptative and generative forms of learning, which occur at the individual, group and organizational level of an organization (Brockerhoff et al., 2014).

Though there is an emergent literature related to group learning, little is known whether organizations change through adaptative processes in their groups (Edmondson, 2002; Stiglitz \& Greenwald, 2014). It is worth noting healthcare research does not distinguish between groups and team (Saltman et al., 2007). In the present study, the term group is preferred.

For Hackman (2011) and Edmondson (2012), groups are understood as units of learning inside organizations and, generally, it is one these groups that the strategies of the organization are transformed into action. Hence, it is fundamental that learning is promoted on groups (Hackman, 2011; Edmondson, 2012).

The set of activities and intentional routines that allow the effective employment of the strategies of the organization objective to maximize the conversion of knowledge in generated value is called practices (Kianto \& Andreeva, 2014). These practices can be transitory, dynamic, and be configured as an answer to changes in the needs of the group (Rerup \& Levinthal, 2014). In this way, over time, groups working together can evaluate results and review their practices.

In this scenario, the objective of this article is to identify and detail practices in the processes of production of diagnostic imaging that support continuous learning in three groups of radiologists. These groups took part in knowledge intensive organizations (Dorow, 2017). Radiology and diagnostic imaging organizations are knowledge intensive due to the low level of predictability, the difficulty in structuring, the automatization of processes, and due to the high complexity involved in decision making (Kim et al., 2012).

The main contribution of this research is to better understand learning in real work groups, thus outlining the practices employed by the analyzed groups and how they support learning.

To reach this objective the article is structured in: introduction, where the context and the objective are presented; theoretical references, where the studied theme is presented; methodological procedures, with the description of the adopted steps in this research; discussion and analysis of the practices identified in the process of production of the diagnostic imaging in the studied groups; final considerations and contributions; and the utilized references.

\section{Literature review}

The theoretical references of this research cover the following themes: workplace learning, learning in group, creating a common objective, performing actions with autonomy, trusting in the members of the group, and utilizing virtual environments.

\subsection{Workplace learning}

An organization learns through actions and interactions that occur between people, groups or teams. These people are oriented both by organizational objectives and by specific objectives of the group in which they take part. (Edmondson, 2002; Holford, 2018). 
These groups may be composed of newcomers or specialists. The specialists have an ability to act autonomously and flexibly, whereas newcomers require more orientation, they require learning (Wilkesmann \& Wilkesmann, 2011).

One of the results after the World Wars in the beginning of the $20^{\text {th }}$ century was the recognition and acceptance of workplace learning, due to the need of transitioning from military knowledge and skill for the requirements of the organization (Rothwell \& Kazanas, 2011). During the 70 s and 80 s, the efforts to promote training were expanded mainly to the cognitive and psychomotor domains, and to broader educational goals, including the preparation for informatics, robotics, engineering and telecommunications technologies (Rowden, 1996). Two recurrent themes of such workplace efforts are performance improvement and informal learning.

Informal learning refers to daily experiences, whether at the workplace or not, where individuals learn something new (Merriam et al., 2012). Authors like Dixon (1997), Marquardt (2011), and Poell (2005) believe most of what is learned at the workplace is informal and is given through the interaction between individuals in small workgroups in training relationships, through orientation, and through networking opportunities.

Even if an organization provides formal sessions for orienting new collaborators, most on-the-job training happens through trial and error and in brief discussions between coworkers. In this stage, newcomers become familiar with available resources, acceptable patterns, and the values of the organization; that is, when not promoted by the administration, on-the-job training can also be considered informal. In this case, generally, the training is conducted by a supervisor or by an experienced coworker. One of the advantages in this process, according to Dyer (1984), is the simulation of conditions that are more aligned with real work duties.

According to Kirkman et al. (2012), a common mistake is consider organizational learning as a synonym of performance improvement. Performance improvement is related to organizational learning when the group effectively learns; thus, organizations focused on the performance reach results in the short term, because performance is required immediately. On the other hand, organizations based on learning focus in the long term and need more time to present results, because they reinvest on learning continuously (Argote, 2012).

Hence, the development of knowledge both in the organization and in their members is considered important, and a learning and a cooperation culture, a physical and technological environment, and an active leadership, when combined with attendance-based and virtual activities, guarantee organizational learning individually and in groups, building transformative and disruptive ways. However, in the accelerated growth rate of knowledge, only individual learning is not enough, it is also necessary to know how to learn in group, as indicated in the following subsection.

\subsection{Learning in group}

In order to direct workgroups, there are organizational leaders who are in charge of supporting the motivation of the group to produce and to perform better their activities, aiming better results. According to Northouse (2007), leadership is a process where the individual influences a group of people to achieve a common goal. Through this definition, it follows that leadership is the process to influence others to understand and agree on what must be done and how it must be done; it is the process of easing individual and collective effort to share objectives (Yukl \& Becker, 2006). 
Leadership support is considered one of the four pillars of knowledge management $(\mathrm{KM})$, and in the case of group learning activities that permeate the processes involved in the improvement of decision making are emphasized (Stankosky, 2005). Devi Ramachandran et al. (2013) conclude leaders can play an important role in the beginning of $\mathrm{KM}$, since they control the environment of knowledge processing.

In the case of a radiology and diagnostic imaging organization, knowledge is effectively processed by a group of radiologists. Dyer (1984) defines a group as two or more people with a common goal, with specific role assignments for each member of the group and interdependence between members. Orasanu \& Salas (1993) describe groups as decision makers in the context of a bigger goal, and these groups have specialized knowledge and skills aligned with their assignments.

According to Huszczo (2004), a workgroup exists when its members choose to spend time and energy interacting and depending on each other, believing a better result may be reached together instead of working independently.

Dechant et al. (1993) believe that most groups do not think about what they do and learn. Instead, these researchers introduced the concepts of learning outcomes and learning processes. The first refers to improvements in group performance measures, new approaches to doing work, new ways of thinking about work or acting in a group, and changes in norms within the group. The second is the combination of thought and action.

Based on the concept of learning through experience, Abbott \& Dalton (1999) identified 32 strategies to learn with new experiences. These strategies are grouped into four categories: action; thought; feeling; and access to other collaborators. Action is to learn through trial and error. Thought includes reflecting on an experience. Feeling is dealing with emotions included in trying something new, such as fear. And accessing collaborators involves obtaining advice from others.

Besides guiding learning practices, the challenge of leadership is also to conduce periods of crisis. Many conceptual and empirical studies addressed the topic organizational crises (Boin et al., 2010; Hale et al., 2005; Weisæth et al., 2002).

The next item addresses the importance of creating a common goal, for it enhances learning insofar as it creates a sense of belonging and commitment in individuals, in relation to various tasks performed by them.

\subsection{Creating a common goal}

The creation of a common goal is particularly important when the members of the groups are dispersed and occupied with their own assignments. Under these circumstances, it is very easy for members to distance themselves from the purpose for which the group is dedicated (Schein, 2006).

Leaders are key in establishing common ground in groups. However, it is necessary to articulate this objective without creating specific guidelines, that is, making it clear the goal is dynamic and will be co-created with the group over time (Howard-Grenville \& Rerup, 2016).

The creating of a common goal is vital for guaranteeing focus and energy for learning, with the generation of a common feeling of commitment and development of coherence between distinct activities (Senge, 1990). Katzenbach \& Smith (1993) also utilize the idea of common purpose for defining a group by stating that a small number of people committed with complementary skills and a common purpose form a group. 
According to Lawrence (2008), for a group to perform its functions in a desirable way its members must have autonomy in carrying out their tasks, reliability to share critical knowledge and an adequate technological structure to also enable interactions outside the physical work environment.

The complexity involved in healthcare, as in the diagnostic imaging area, does not allow a partial resolution of problems. In order to solve complex diagnostics efficiently, only collective actions can provide better results, which compose the next item's topic.

\subsection{Performing actions autonomously}

A group learns when there is the possibility to test new ways of reaching its objective. Expecting that a group follows a set of predefined steps implies that the solution will always be the same, which suggests a way for this solution may be planned without demanding much reflection (Hoch \& Kozlowski, 2014). A complex objective demands that groups attempt to adapt and reflect on their results and review their errors. According to Hackman (2011), when the individuals of a group try alternative ways to move on with their work, probably their comprehension of how to reach the planned result increases. In this way, during effective action it is possible to find possible ways of improving the conduction of activities and interact with the leader about possible reviews in the performed activities.

Individual autonomy is defined as a degree in which work offers substantial freedom, independency and discretion to the individual in the work schedule and in determining the schedule's procedures (Hackman, 1983). Individual autonomy also refers to the reasoning and control that an individual has on the implementation of a task assigned within the group (Benson, 2013).

On the other hand, group autonomy is the amount of control that an organization allows to the group in terms of task implementation, schedule and, in some cases, even task designation. Group autonomy is the amount of decision making about the activities assigned by the organization, it is a measure of the group's freedom to perform tasks within the organization, it is not related with the group's internal processes, and it may be reflected by the authority of the group leader. Group autonomy is not the association of individual autonomy in the group level, but a group-level construct that is not significantly expressed individually. The cohesion of a group may be considered the degree in which the members of the group positively identify with the group itself (Hackman \& Morris, 1975). The cohesion of a group may also be considered the existence of strong ties within a group, or to what extend the members of the group wish to remain members of the group (Shaw, 1971).

Hackman (2011) further clarifies in his research that goal-oriented group work allows room for experimentation, which produces learning. Learning is influenced by several elements, with the motivation and ability to do something. In addition, trust is a key element for group learning. This subject is addressed in the next item.

\subsection{Trusting in members of the group}

Authors such as Becerra \& Gupta (2003), Gulati \& Sytch (2008), Hansen et al. (2008), and Holford (2016) outline trust may lead to a cooperative behavior that is more effectively articulated between individuals, groups and organizations. 
Some studies also identify factors such as cultural differences and kind of knowledge are vital for the sharing of knowledge, also indicating reliability as an important facilitating factor (Easterby-Smith et al., 2008). Among the factors that influence the creation of trust are: personality traits; cognitive clues; social structures; situational factors; beliefs; and emotions.

Therefore, to occur group learning, its members must act in way that the knowledge of each individual is available for the whole group. Edmondson (1999) points out some actions that each member may perform to demonstrate his knowledge is freely available: seeking feedback; sharing knowledge, particularly, the unique knowledge each member possesses; asking for help; testing hypotheses; discussing differences and opinions openly, instead of doing it privately or outside the group; speaking out errors; and experimenting and reflecting together about the results. Through such actions groups may detect changes in the environment, get to know the requirements of customers, improve the collective comprehension of their members about a situation or even discover unexpected implications of their previous actions (Edmondson, 1999).

Another condition that promotes interactions within the group is the presence of psychological security through a more active role in the construction of limits, which implies responsible engagement. These commitments require trust between the parties, which, in turn, requires the involvement of the management in providing a psychological safety network in the workplace through the cultivation of mutual trust and respect (Holford, 2016).

The use of such actions for learning in group may seem obvious, however, individuals present great difficulty in carrying out these actions, mainly due to the need of exposing their knowledge and reputation; that is, asking for help requires admitting a possible lack of knowledge. In the same way, seeking feedback or admitting an error may lead other individuals to perceive their coworker as incompetent.

With explanation of the possible causes of these concerns, the individuals, in order to express a learning behavior, must feel safe between their peers. Edmondson (2012) describes security as a sense of trust that the group will not disorient, reject or punish someone for speaking. Security goes beyond interpersonal trust and also involves: a) respecting the other's competence; b) taking care of one another as people; and c) trusting one another's intentions. In this way, the group will develop a shared sense of safety, which is developed through shared experience.

These shared experiences build up, over time, a shared belief and tacit that the group is a psychologically safe context to exercise the learning behaviors listed beforehand.

In this same line of thought, Nilsson \& Mattes (2015, p. 231) define trust as the intention or will to accept vulnerability based on positive expectations from the intentions and behavior of others. Initial trust is based on belonging to a group, receiving information about members of the group from third parties, trusting on the system and having a shared interest. Gradual trust results from the repetition of interactions over time and is based on: knowing the capability of others to execute a specific task; trusting in the individual to execute the task at hand; and witnessing integrity and kindness of the colleague during a work situation (Suh et al., 2011). Since the initial trust is not based on experience, it is fragile. Thus, a mistake or misunderstanding may easily destroy initial trust (Bigley \& Pearce, 1998). Gradual trust is more resilient and may support such incidents. 
Trust, then, enhances the collaboration between the members of the group. A great way to exercise the collaboration between groups is through virtual activities, where all members of the group share their opinions, experiences and curiosities, as addressed in the next item.

\subsection{Using virtual environments}

According to Litchfield et al. (2015), in order for virtual workgroups to be effective, it is fundamental that initially a face-to-face meeting between the members takes place. There is a growing evidence that groups that create routines, such as sporadically participation in face-to-face meetings, maintain a level of security and trust that encourages a learning behavior and improves the connectivity and feeling of belonging (Hoch \& Kozlowski, 2014).

Maznevski \& Chudoba (2000) discovered regular in-person meetings is essential for the efficacy of sharing in virtual environments, in the case of tasks that demand a high degree of interdependence. The authors also complement the frequency of in-person meetings is related to the level of interdependency demanded by the task, to the degree of shared view, and to the strength of relationship of the members. Over time, individuals interacting in virtual environments can make effective choices regarding the communication supported by the technology, which must be used to face different kinds of problems. The authors also mention having a planned and regular communication through technology increases the group's efficacy.

Thus, it is possible to state learning is the result not only of individual actions that the individual experiments, but also the incentive of the organization, which, through leadership, can create physical and virtual environments to stimulate trust, where the professionals are autonomous, and to stimulate common objectives to learn at work (Dorow, 2017). In this context, this work seeks to identify and detail practices in the processes of production of diagnostic imaging that support the continuous learning in groups of radiologists.

\section{Methodological procedures}

This is an applied research because it collaborates to practical purposes (Creswell, 2010). Regarding the approach, this is a qualitative research with the purpose of identifying and detailing how the specific group practices carried out in the diagnostic imaging processes of three groups of radiologists support their continuous learning. It is descriptive, because it is proposed to know and interpret reality, not change it (Churchill \& lacobucci, 2006). This kind of research utilizes techniques that involve the interpretation to describe and translate all the elements that compose the researched data. It is sought to obtain descriptive data about a given theme from data collected with interviewed individuals. As technical procedure, a multiple case study was utilized, applied in more than one population.

The research's universe was composed of three groups belonging to radiology and diagnostic imaging organizations located in Santa Catarina (Dorow, 2017). The medical diagnostic imaging performed by the three groups ranges from routine exams to highly specialized exams. Such groups are identified by the organization to which they belong, called in this study O1 (Organization 1), O2 (Organization 2), and O3 (Organization 3). To select these organizations, the following criteria were utilized: the members of the 
studied group have less than 10 years of work experience; the organization utilizes the Picture Archiving and Communication System (PACS); and the studied group presents a leader.

The subjects of the study were 43 medics specialized in radiology and diagnostic imaging. Among them, 22 were novices and 21 were experienced. The research was employed between the June 2016 and January 2017, according to the availability of the interviewees. Initially, observations were made for a period of 15 days in each of the three participating groups, aiming to understand the activities performed by the groups in the process of producing diagnostic imaging and how they supported the continuous learning of the groups.

Then, interviews were carried out with the help of an unstructured script directed to radiologists, with questions that allowed a better fluidity of information, without inducing any response and allowing new reflections on the subject.

The main subjects of the script covered questions related to the perception of: a) the activities performed in the production of diagnostic imaging and its objective; b) the practices performed during the execution of each activity; and c) the role of the leader during the activities (Dorow, 2017). 43 interviews were carried out, 21 with members of the first group, 12 of the second, and 10 of the third.

The data collected during the investigation and the interviews were analyzed through thematic analysis (Santos, 2012), which lead to common points in the collected data. This technique is employed in three steps: i) pre-analysis; ii) exploration of the material; and iii) treatment of the results and interpretation. Choosing the thematic analysis as methodology was appropriate because its main function is to critically uncover and discover relations between the discourse content and the exterior aspects, both surrounding the theme addressed in this research. The interviews were recorded.

After the interview was carried out, they were transcribed and analyzed according to thematic analysis criteria. Each interviewee received a code so that the organization that he belonged could be identified, e.g. O1E4.

i) Pre-analysis: the analysis began with a floating reading, so that initial impressions regarding the material to be analyzed were produced). In the case of this study, the analysis corpus derived from the information resulting from the transcription of the applied questions;

ii) Exploration of the material: in this step, the information contained in the material was coded, that is, the interviews were classified in thematic categories;

iii) Treatment of the results and interpretation: to analyze the obtained data, the researcher had expressive and safe results, which allowed to suggest inferences and anticipate interpretations in accordance with the objectives, or even in relation to other unexpected findings. Then, three main categories emerged from the data and were identified after data analysis processes: a) organizational structure (activities to share and to solve problems); b) identification of problems and learning practices; c) motivation mechanism of the leaders.

By coding the interviews, patterns emerged and were validated during the interviews. A final interview with the leader of each of the three groups was also very important to validate the categories resulting from the data analysis. 


\section{Results analysis and discussion}

From the immersion of the researcher into the data (that is, from the repeated interactions between the interviews, collected facts from the secondary literature and the data analysis), a structuring of the production process used by the radiologists to find a diagnosis emerged. Brief descriptions of the research findings are presented below.

Organization 1 has 25 years of experience, 21 radiologists, 9 novices and 12 experts. Carries out the following exams: MRI, computed tomography, ultrasonography, mammography, bone densitometry, digital radiology and interventional radiology. Utilizes PACS. Organization 2 has 10 years of experience, 12 radiologists, 7 novices and 5 experts. Carries out the following exams: MRI, computed tomography, ultrasonography, mammography, bone densitometry, digital radiology. Utilizes PACS. Organization 3 has 22 years of experience, 10 radiologists, 6 novices and 4 experts. Carries out the following exams: MRI, computed tomography, ultrasonography, mammography, bone densitometry, digital radiology. Also utilizes PACS (Dorow, 2017).

In the three organizations, the members of each of the three groups carried out their activities in-person and in the same room, in the "report room", which allowed constant communication between them. They also had technological support to carry out virtual interactions, both between members of the group and with other groups from outside the organization.

In the three analyzed groups, knowledge is created through a common understanding, mainly by carrying out difficult diagnostics, both during the organizational routine and through virtual interaction between individuals from groups from collaborating organizations. The interaction with groups from collaborating organizations occurred mainly through information and communication technologies in virtual environments (Dorow, 2017).

Image 1 presents the process of diagnostic production, its respective activities carried out in the studied organizations and the way that each group acts in the process of producing the diagnosis. This process consists in activities that are complementary for the making of the diagnostic imaging. The process also explains the chain of value of the organization and the organizational knowledge that emerge from the activities network, through which each group establishes common understandings on how to act in each situation. The execution - or absence - of each of these activities is identified by its corresponding trajectory and reflects the routines learned by each group of the organizations addressed in this research after going through positive and negative experiences, in dealing with repetitive situations that are part of the radiodiagnosis decision-making. 


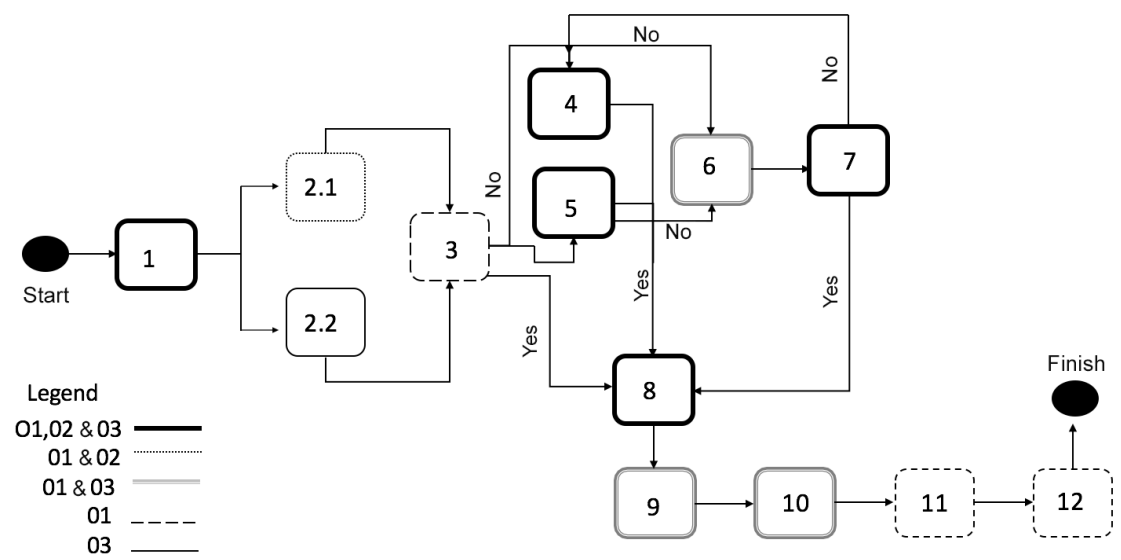

Figure 1. The process of producing diagnostic imaging. Fonte: The authors (2017).

As shown in the image, 12 activities compose the process of diagnosis production, namely: 1) receiving the image; 2 ) types of performance; 2.1 ) acts only in his domain; 2.2) acts outside his domain; 3) query the database; 4) knowledge sharing in the organization; 5) knowledge sharing among organizations; 6) discussion of the case at the group meeting; 7) sending the image to external organizations; 8) conclusion of the diagnosis; 9) review of the diagnosis; 10) discussion in case of divergence of diagnostic opinion; 11) including the image and the report in the image bank; and 12) supplying more data for the image bank. The arrows indicate the path from beginning to end. The word "no" means that the activity was not enough to solve the problem and in the case of "yes" the path follows its normal flow. The legend indicates the execution of each of these activities - or lack of thereof - by one of the three organizations, identified by the correspondent stroke.

The objective of each of these activities is the strategic management of knowledge, in order to aggregate value to the final product, i.e., the diagnosis. The radiologists' understanding each of these activities is collective, as it is the result of diffuse dialogue, which leads to the sharing of interpretations. These dialogues are considered eased by practices and supported by technology. These activities from the process (Image 1) are detailed next.

The process begins with the activity receiving the image (1) through PACS. As observed, the adoption of PACS ensured the optimization of the workflow, the improvement of the processes and the integration between all the steps involved in carrying out an image examination.

In relation to the activity types of performance (2), two forms of work were identified: 2.1) diagnosing only in his domain, that is, the radiologist works only within his subspecialty (cardiology, neurology, etc.); and 2.2) diagnosing outside his domain, in which case the radiologist may also interpret images outside his subspecialty. In both forms, the individual has the autonomy to experiment (put his knowledge into action) and to make the diagnosis.

The activity querying the image bank for comparison (3) allows to support the diagnosis - which allows the tacit knowledge (experiences) of radiologists is not exclusive to their own minds; it can be explained through reports and used by other radiologists. This reinforces the idea of "similarity in a similar respect" and pre-reflection by Adloff et al. (2015). This explicit knowledge allows the formation of the practice of organizational memory, which serves as support and example for other related 
diagnoses, both by comparing other images and as a model of the reasoning used, as one of the interviewees explains:

We update the image bank with knowledge that is learned. It is important that it be supplied, as it serves as a basis for consultation and in some cases, it is where one looks at how the diagnosis was carried out and based on this to conclude the report. When we learn something critical, we externalize the behavior and insert it into the image bank. (O1E16).

However, it is important to emphasize that for this image bank to work as a diagnosis support tool, it depends on constant revision and updating with new cases and new knowledge (memory). Thus, every time a critical or complex diagnosis is identified and resolved, it is added to the imaging database (along with a descriptive text), providing novice radiologists with elucidative examples of various types of pathologies. This is a tool that primarily helps novice radiologists. The comparison of new images with already diagnosed similar images and the explanation of the reasoning used to carry out the diagnosis help in the reduction of uncertainties, as stated by one of the interviewees:

In the residency, for four years we train by seeing the differences between normal and abnormal images to learn to differentiate. This is done in a clinical setting and we receive feedback from another, more experienced radiologist about our work, showing why something is abnormal; but there is no way to see all the characteristics represented in different types of images during the residency, so there is always something that you did not see. When something that I do not know or I have doubt appears, I always use the image bank to compare the image and to understand the diagnostic reasoning that was used. (O1E21).

Every time a problem related to a critical diagnosis is solved, this new experience is retained and added to the image bank and is available for future diagnoses, as the creator of this diagnostic support tool reveals:

Using previous cases to support medical decision is not something new, the hard part is for you to build a consistent foundation, to update it, and to constantly reupdate it. With my experience, I realized that this would work, but it would be very beneficial in the long run. I realized that reading the signs and symptoms of a new patient's medical request reminded me of the history of another patient's illness by presenting a similar set of symptoms and following a similar path, and today, we actually use this database of images and it brings us many advantages. We make a selection where we evaluate the relevance, reliability and usefulness of the images, usually from critical diagnostics, to compose the image bank. (O1E1).

When questioned about the use of the imaging database, the radiologists reported they use this support tool and also pointed out the following advantages: it shortens the time of diagnosis; it captures and reuses the experience of other radiologists and allows constant learning through image association.

This practice of recording past experiences through a database of images to solve new diagnoses so that their access is quick and easy was perceived as a facilitator for the success of diagnoses and as a way for radiologists to learn (Dorow, 2017). 
The results of this research coincide with the study by Cyert \& March (1963) that coined the term "organizational learning" and suggested organizations are rational adaptive systems that basically learn from experience. In addition, Mauchet's (2011) study evaluated the importance of organizational memory in health organizations and recognizes memory allows recognizing valuable knowledge and also allows understanding how this knowledge is interpreted. The new knowledge, as interpreted, is added to the organization's memory, and may involve, as supported by Barr et al. (1992), the unlearning of some previously held beliefs. The organization is then challenged by its history, which changes the perception of the meaning of new knowledge.

The activity sharing organizational knowledge (4) can be performed before, after or consecutively to the sharing of interorganizational knowledge, presented next. However, for the most part, this is the first choice for addressing problems, since there is a sense of cooperation and trust in the groups (Dorow, 2017). This activity represents the exchange of knowledge between the work network inside the group, and it can be carried out inside (face to face) or outside the group (supported by technology).

Regarding the activity of sharing interorganizational knowledge (5), according to Dorow (2017), the ease of access, through the PACS, becomes fundamental for the radiologists to send images to external colleagues (networking). The discussion of critical diagnoses supported by PACS enables the generation of new knowledge. However, consulting an external radiologist can also occur informally, when the radiologist has a relation of friendship and cooperation with an external specialist. In contrast, this activity of sharing of knowledge between organizations is done in a formal way. However, this is only done when the group, internally, has already exhausted its attempts and is not able to solve the diagnosis.

In the activity of taking the case for discussion at the group meeting (6), the objectives of these meetings may be: a) solving diagnoses through consensus among the group of radiologists; b) discussing critical cases; c) sharing new internal knowledge with the group; and d) sharing external knowledge that has been learned with radiologists from other groups outside the organization.

The activity sending the image to another group to share external knowledge (7) happens when the attempts to solve the question have been exhausted internally. In this case, the group makes use of its networking, that is, of its relations with external organizations to solve uncertainties. Thus, the group sends the image to another group belonging to another organization so that it is resolved, as one of the radiologists reports:

We have a network of contacts, other units of radiology, that we have a relationship of mutual cooperation. The radiologist that is most involved with the case in question learns how to solve the matter with one of the radiology centers that we have contact with, via PACS, and later, this radiologist passes what he has learned to all the other members of the group. (O2E2).

This sharing of knowledge among other groups, supported by the PACS system, allows the group to use its networking to facilitate (interorganizational) learning and build new knowledge to accompany the exponential growth of the imaging area (Dorow, 2017).

The activity completing the diagnosis (8), represents the completion of the process for Organization 2, the only one that does not perform any type of diagnostic review.

The activity reviewing the diagnosis (9), guarantees greater assertiveness and assertiveness to the diagnosis, as observed in the speeches of the radiologists of each of the three organizations: 


\begin{abstract}
We carry out a review of all diagnoses. This brings us many advantages. The important I would say is the opportunity for continuous learning for our group because we do not try to punish mistakes but to learn from them. The second is the assurance of greater assertiveness of the diagnosis, which also helps us to maintain the quality of our product. (O1E16).
\end{abstract}

We do not have a formal review because we do this during our work routine, as needed. As we are a small group, it is easy to ask for the second opinion of a colleague if there it is needed, but I consider that a second opinion undoubtedly improves the quality of the diagnosis. (O2E12).

We have double signatures only in the tomography and resonance examinations, which by nature are more difficult, the others I believe that there is no such need. If the radiologist feels the need, he can always count on the help of his colleagues. (O3E6).

There are two objectives in the peer review, called by the participants the "double signature". One is to get a more assertive final diagnosis, the other is the feedback from the work, provided by the second radiologist. It has been observed the formal peer review practice also acts as an activator for new knowledge sharing.

In the discordance activity during the peer review (10), if there is a disagreement between the diagnostic opinion of two radiologists, they talk until a consensus on the diagnostic decision is reached. This review allows the identification of fragilities in knowledge, both individually and in the group. This discussion helps to decrease the group's learning curve and to create common understandings.

The report inclusion activity (11) is to add images and diagnostic reports in the imaging database, and the activity of the image database (12) precedes the end of the diagnostic process. The option of including the diagnosis in the image bank, as already discussed, depends on the criticality of the diagnosis (Dorow, 2017).

Considering the presented activities, another distinctive element for the effective accomplishment of each activity was the organizational leadership, which acts in the planning, execution and evaluation of the results of the activities performed. In the three groups observed, the leader, besides being part of the group, is also a radiologist. In the group from $\mathrm{O} 3$, formal leadership is complemented by shared leadership, where group radiologists also informally assume leadership responsibilities in different ways and on several occasions. One of the statements of the interviewees reinforces the importance of the leader so that the whole process is smooth:

As our group is small, our networking is very important and creating a network is not trivial. Our leader works coordinating and motivating the group, also acts in the search of new work partners. Since he is involved in every work process, it is easier to understand what needs to be done, from the purchase of an equipment to a specific training. No doubt he really has an ability to solve problems. (O2E10)

In this sense, since in all three groups the group leader is a radiologist the understanding of the environment is eased, given that he has full knowledge of the diagnostic activity, which guides a more meaningful action.

During the interviews, the radiologists indicated the skills they considered important in a leader, such as: also being a radiologist in the group, to better understand what is relevant during the diagnostic process; recognizing, stimulating, coordinating and motivating the work of the radiologists of the group; using internal and external 
knowledge effectively; indicating theoretical material and practical cases that are interesting and relevant; leading the sharing of internal and external knowledge; increasing the networking of the group; encouraging informal socialization among group members; identifying the need to acquire new technology; presenting new knowledge when necessary; providing feedback regarding the radiologist's work; and planning discussions for the group's formal meetings (if the group carries them out).

There are several activities in the process of production of the diagnosis (according to Figure 1) where each group perceives, shares and uses their knowledge in a singular way and has its standardized activities, in relation to the actions that seek to procure, evaluate and choose alternatives for the resolution of the diagnosis.

In general, when analyzing the execution of the presented activities, the first group was observed to perform the greatest number of activities to strategically manage knowledge, followed by the third and the second group.

The groups from $\mathrm{O} 1$ and $\mathrm{O} 2$ direct their radiologists to perform the imaging diagnosis only within their domain, with the exception of radiologists who do not have a subspecialty. The advantage of this form of work is that the skill can be reached in a shorter time, due to the intensity of repetition of the diagnoses, according to of the interviewees:

No doubt, it is better for us to work only in a subspecialty. First, if you chose it, it is because you have affinity with it. Second, when delimiting an area and practicing only that area ends up being faster to master that. (O2E4).

Thus, focusing on a subspecialty is positive for those radiologists who aim to master a specific one. However, the deliberate practice among the different domains of diagnostic imaging leads to a more generalized training, allowing the radiologist to be more familiar to perform diagnoses in different areas. This aspect is reinforced by one of the interviewees:

We end up seeing all, having a more superficial and broad knowledge. The good thing is that over time you end up feeling more comfortable in reporting various types of images. I like it because I can fit in anywhere, as our work group here is small, we do a little of everything, if one is not around the other needs to know how to do, if we have something complex, we send it by PACS and we carry it anyhow. O3E7

The characteristic of the more generalized work is an option of both the organization and the professional and, as explained this interviewee, thanks to the available technology (PACS), even if the group does not have the necessary knowledge to perform complex diagnoses, it can be sent to a specialist in the subject or to other groups (virtual teams) to be carried out, not hindering the diagnosis (Dorow, 2017).

The three groups collaborate as a means to improve decision making and meet the challenges of competitive environments that could not be achieved by themselves. It is important to note the registration of learned new knowledge prevents the organization from having to rework to create the knowledge it already has.

The results of this research support the three requirements identified in the literature that address group learning: (i) concordant objectives (Howard-Grenville \& Rerup, 2016); ii) autonomy to experiment (Hackman, 2011); and iii) an environment of cooperation and trust (Hansen et al., 2008).

Regarding these requirements, eight learning practices were identified, especially when the group members are in person together; namely: a) receiving and seeking direct feedback; b) routine interactions in the report room (storytelling); c) specialist / novice tutoring (mentoring); d) best practices, held at group meetings for discussion; e) lessons 
learned, a practice also identified in group meetings; f) sharing of knowledge with other external groups, supported by technology through established networking (benchmarking); g) peer review (double signature) that makes allows the identification of gaps both in the knowledge of the individual and the fragilities of the group; and h) organizational memory, which is effective through the image bank (Dorow, 2017).

In relation to virtual environments, two practices occur: discussion forums and virtual collaborative spaces. These environments also contribute to group learning.

\section{Final considerations}

This article contributes to the minimization of a gap in the literature (Burgoyne \& Hodgson, 1983; Marsick \& Watkins, 2001; Mumford \& Gold, 2004) by detailing how group individuals learn and work together to carry out and modify the activities that produce and deliver services to customers. Most often, a group-level perspective on organizational learning emphasizes interpersonal perceptions and behaviors.

The lens of this research focused on the interactions between a small number of individuals and on how they initiate new actions and improve or inhibit the process of building new knowledge.

The organizational environment where such learning is takes place is significant in relation to the meaning attributed to learning by individuals, to how they learn and to what they seek to learn. In addition, the characteristic of group size and side-by-side work creates opportunities for ongoing interaction among group members and fosters cooperation and confidence-building.

The identified practices are particular to the environment and to the activities performed by the studied groups. Therefore, the specific practices of one organization are not transferable to another organization.

The group practices employed when groups work together physically differ from practices employed when groups are working virtually, though they serve a similar purpose. According to the literature, practices can and should change over time in response to changes in the environment and the nature of the activities. The occurrence of each practice is established by the level of autonomy of the activity, and the greater the autonomy, the greater the occurrence of the practice.

Regardless of the occurrence, practices happen continuously and not in isolation. The main practice that supports the goals of organizations and improving diagnostic assertiveness is peer review. Group meetings allow for a set time for groups to discuss and reflect together, and learn from each other, which they can do differently.

The characteristics that help to develop confidence and security include the longtime experience and coexistence among the members of the group; the small size of the groups; the opportunities for group members to learn by telling stories about their experiences and demonstrating their knowledge; the review of diagnoses that makes it possible to identify the strengths and weaknesses of colleagues; and the use of sophisticated technology that enables the sending of images for discussion and openly dialoguing.

In general, in the studied groups, the specialists teach the novices and also learn from them. Evidence from this research demonstrates a radiologist can be considered both a beginner and a specialist at the same time. This is due to the fact that there are distinct knowledge bases involved in the process of diagnostic imaging. Consequently, a specialist in a domain area interacts with a specialist from a different domain and develops his knowledge. This result confirms the study by Wilkesmann 
\& Wilkesmann (2011), who stated the longer an individual works in a domain, the more experience that individual develops in that particular domain.

In the three studied groups, it was possible to perceive organizational learning occurs when radiologists experience a problematic situation and share knowledge, motivated by their curiosity and the culture of protecting the organization's name. This confirms Hedberg's (1979) research, that is, organizations have no other brains and senses beyond their members, even if organizations share knowledge, intra- or interorganizational, knowledge sharing processes always include the individual level.

Based on the results, it is possible to infer it is the responsibility of the group leader to create and encourage learning practices, observe the work of the groups over time to determine if these practices are sufficient, and to establish new practices if necessary. In this way, group leader behaviors that encourage discussion result in activities that require interaction and feedback and help nurture a healthy cycle of reflection and action to achieve organizational goals.

Furthermore, during this research differences in the speed and capacity of learning between the groups were identified. This distinction was evidenced by the capacity in the execution of different diagnoses and the development of the knowledge of the groups and individuals. The greater speed and learning capacity are thus associated with greater interaction of individuals in the organization (intraorganizational) and with other groups (interorganizational) resulting from the collaborative characteristic of work, culture, active leadership and interoperability supported by technology. Learning with groups outside the organization was common among the studied groups and is one way to deal with the speed of changes in healthcare. This study also allowed to compare the efficiency with other healthcare groups and to learn with their collective actions.

Thus, this research suggests a culture of personal and professional development that supports learning is fundamental to the sharing of knowledge. This aspect was distinctly identified in the three studied groups. Thus, continuous learning can be understood as one of the organizational culture elements and this learning culture contributes to a flexible view of the radiologist, creating transforming and disruptive paths.

The evidence from this research may also contribute to the review of the organizational activities performed during the diagnostic production process, adapting or adding knowledge strategies (activities) that help to minimize diagnostic errors.

\section{References}

Abbott, A., \& Dalton, R. (1999). A post-genomic challenge: learning to read patterns of protein synthesis. Nature, 402(6763), 715-720. http://dx.doi.org/10.1038/45350. PMid:10617183.

Adloff, F., Gerund, K., \& Kaldewey, D. (2015). Revealing tacit knowledge: embodiment and explication (Vol. 2). Bielefeld: Transcript.

Argote, L. (2012). Organizational learning: creating, retaining and transferring knowledge. Heidelberg: Springer.

Barr, P. S., Stimpert, J. L., \& Huff, A. S. (1992). Cognitive change, strategic action, and organizational renewal. Strategic Management Journal, 13(S1), 15-36. http://dx.doi.org/10.1002/smj.4250131004.

Becerra, M., \& Gupta, A. K. (2003). Perceived trustworthiness within the organization: the moderating impact of communication frequency on trustor and trustee effects. Organization Science, 14(1), 32-44. http://dx.doi.org/10.1287/orsc.14.1.32.12815. 
Benson, P. (2013). Teaching and researching: autonomy in language learning. London: Routledge. http://dx.doi.org/10.4324/9781315833767.

Bigley, G. A., \& Pearce, J. L. (1998). Straining for shared meaning in organization science: problems of trust and distrust. Academy of Management Review, 23(3), 405-421. http://dx.doi.org/10.5465/amr.1998.926618.

Boin, A., Hart, P., McConnell, A. L. L. A. N., \& Preston, T. (2010). Leadership style, crisis response and blame management: the case of hurricane Katrina. Public Administration, 88(3), 706-723. http://dx.doi.org/10.1111/j.1467-9299.2010.01836.x.

Brockerhoff, L., Stensaker, B., \& Huisman, J. (2014). Prescriptions and perceptions of teaching excellence: a study of the national 'Wettbewerb Exzellente Lehre'initiative in Germany. Quality in Higher Education, 20(3), 235-254. http://dx.doi.org/10.1080/13538322.2014.978134.

Burgoyne, J. G., \& Hodgson, V. E. (1983). Natural learning and managerial action: a phenomenological study in the field setting. Journal of Management Studies, 20(3), 387399. http://dx.doi.org/10.1111/j.1467-6486.1983.tb00214.x.

Churchill, G. A., \& lacobucci, D. (2006). Marketing research: methodological foundations. New York: Dryden Press.

Creswell, J. W. (2010). Projeto de pesquisa métodos qualitativo, quantitativo e misto. In J. W. Creswell (Ed.), Projeto de pesquisa métodos qualitativo, quantitativo e misto. Porto Alegre: Artmed.

Cyert, R. M., \& March, J. G. (1963). A behavioral theory of the firm. Englewood Cliffs: Prentice Hall.

Dechant, K., Marsick, V. J., \& Kasl, E. (1993). Towards a model of team learning. Studies in Continuing Education, 15(1), 1-14. http://dx.doi.org/10.1080/0158037930150101.

Devi Ramachandran, S., Chong, S. C., \& Wong, K. Y. (2013). Knowledge management practices and enablers in public universities: a gap analysis. Campus-Wide Information Systems, 30(2), 76-94. http://dx.doi.org/10.1108/10650741311306273.

Dixon, N. M. (1997). The hallways of learning. Organizational Dynamics, 25(4), 23-34. http://dx.doi.org/10.1016/S0090-2616(97)90034-6.

Dorow, P. F. (2017). Compreensão do compartilhamento do conhecimento em atividades intensivas em conhecimento em organizações de diagnóstico por imagem (Tese de doutorado). Universidade Federal de Santa Catarina, Santa Catarina.

Dyer, J. L. (1984). Team research and team training: a state-of-the-art review. Human Factors Review, 26, 285-323.

Easterby-Smith, M., Lyles, M. A., \& Tsang, E. W. (2008). Inter-organizational knowledge transfer: current themes and future prospects. Journal of Management Studies, 45(4), 677690. http://dx.doi.org/10.1111/j.1467-6486.2008.00773.x.

Edmondson, A. (1999). Psychological safety and learning behavior in work teams. Administrative Science Quarterly, 44(2), 350-383. http://dx.doi.org/10.2307/2666999.

Edmondson, A. C. (2002). The local and variegated nature of learning in organizations: a grouplevel perspective. Organization Science, 13(2), 128-146. http://dx.doi.org/10.1287/orsc.13.2.128.530.

Edmondson, A. C. (2012). Teaming: how organizations learn, innovate, and compete in the knowledge economy. United Kingdom: John Wiley \& Sons.

Gulati, R., \& Sytch, M. (2008). Does familiarity breed trust? Revisiting the antecedents of trust. Managerial and Decision Economics, 29(2-3), 165-190. http://dx.doi.org/10.1002/mde.1396.

Hackman, J. R. (1983). Designing work for individuals and for groups. In J. R. Hackman, E. E. Lawler \& L. W. Porter (Eds.), Perspectives on behavior in organizations (pp. 242-256). New York: McGraw-Hill. 
Hackman, J. R. (2011). Collaborative intelligence: using teams to solve hard problems. San Francisco: Berrett-Koehler Publishers.

Hackman, J. R., \& Morris, C. G. (1975). Group tasks, group interaction process, and group performance effectiveness: a review and proposed integration. Advances in Experimental Social Psychology, 8, 45-99. http://dx.doi.org/10.1016/S0065-2601(08)60248-8.

Hale, J. E., Dulek, R. E., \& Hale, D. P. (2005). Crisis response communication challenges: building theory from qualitative data. Journal of Business Communication, 42(2), 112-134. http://dx.doi.org/10.1177/0021943605274751.

Hansen, M. H., Hoskisson, R. E., \& Barney, J. B. (2008). Competitive advantage in alliance governance: resolving the opportunism minimization - gain maximization paradox. Managerial and Decision Economics, 29(2-3), 191-208. http://dx.doi.org/10.1002/mde.1394.

Hedberg, B. (1979). How organizations learn and unlearn. Stockholm: Arbetslivscentrum.

Hoch, J. E., \& Kozlowski, S. W. (2014). Leading virtual teams: hierarchical leadership, structural supports, and shared team leadership. The Journal of Applied Psychology, 99(3), 390-403. http://dx.doi.org/10.1037/a0030264. PMid:23205494.

Holford, W. D. (2018). An agential realist perspective on the construction and flow of knowledge: the case of dynamic entanglement and "cuts" within an aircraft engine manufacturing workplace. Journal of Knowledge Management, 22(7), 1442-1470. http://dx.doi.org/10.1108/JKM-08-2017-0342.

Holford, W. D. (2016). Boundary contructions as knowledge flows within and between workgroups. Knowledge Management Research and Practice, 14(1), 4-14. http://dx.doi.org/10.1057/kmrp.2014.18.

Howard-Grenville, J., \& Rerup, C. (2016). A process perspective on organizational routines. In A. Langley \& H. Tsoukas (Eds.), The SAGE handbook of organization process studies (pp. 323-337). Los Angeles: SAGE.

Huszczo, G. E. (2004). Tools for team leadership: delivering the X-factor in team excellence. Palo Alto: Davies-Black Publishing.

Katzenbach, J. R., \& Smith, D. K. (1993). The discipline of teams. Boston: Harvard Business Press.

Kianto, A., \& Andreeva, T. (2014). Knowledge management practices and results in serviceoriented versus product-oriented companies. Knowledge and Process Management, 21(4), 221-230. http://dx.doi.org/10.1002/kpm.1443.

Kim, Y. M., Newby-Bennett, D., \& Song, H. J. (2012). Knowledge sharing and institutionalism in the healthcare industry. Journal of Knowledge Management, 16(3), 480-494. http://dx.doi.org/10.1108/13673271211238788.

Kirkman, B. L., Gibson, C. B., \& Kim, K. (2012). Across borders and technologies: advancements in virtual teams research. In S. W. J. Kozlowski (Ed.), The Oxford handbook of organizational psychology (Vol. 2). New York: Oxford University Press.

Lawrence, D. (2008). From chaos to care: the promise of team-based medicine. New York: Da Capo Press.

Litchfield, R. C., Gilson, L. L., \& Gilson, P. W. (2015). Defining creative ideas: toward a more nuanced approach. Group \& Organization Management, 40(2), 238-265. http://dx.doi.org/10.1177/1059601115574945.

Marquardt, M. J. (2011). Building the learning organization: mastering the five elements for corporate learning. Palo Alto: Davies-Black Publishing.

Marsick, V. J., \& Watkins, K. E. (2001). Informal and incidental learning. New Directions for Adult and Continuing Education, 2001(89), 25-34. http://dx.doi.org/10.1002/ace.5. 
Mauchet, M. (2011). Managers' perceptions of organizational learning and organizational innovativeness in a global healthcare organization (Doctoral dissertation). The George Washington University, Washington.

Maznevski, M. L., \& Chudoba, K. M. (2000). Bridging space over time: global virtual team dynamics and effectiveness. Organization Science, 11(5), 473-492. http://dx.doi.org/10.1287/orsc.11.5.473.15200.

Merriam, S. B., Caffarella, R. S., \& Baumgartner, L. M. (2012). Learning in adulthood: a comprehensive guide. San Francisco: John Wiley \& Sons.

Mumford, A., \& Gold, J. (2004). Management development: strategies for action. CIPD Publishing.

Nilsson, M., \& Mattes, J. (2015). The spatiality of trust: factors influencing the creation of trust and the role of face-to-face contacts. European Management Journal, 33(4), 230-244. http://dx.doi.org/10.1016/j.emj.2015.01.002.

Northouse, P. (2007). Leadership theory and practice (4th ed.). Thousand Oaks: SAGE.

Orasanu, J., \& Salas, E. (1993). Team decision making in complex environments. In G. A. Klein, J. Orasanu, R. Calderwood \& C. E. Zsambok (Eds.), Decision making in action: models and methods. Norwood: Ablex Publishing.

Poell, R. F. (2005). Learning organizations and communities of practice: a critical evaluation. In J. P. Wilson (Ed.), Human resource development: learning and training for individuals and organizations (pp. 99-110). London: Kogan Page.

Rerup, C., \& Levinthal, D. A. (2014). Situating the concept of organizational mindfulness: the multiple dimensions of organizational learning. In G. Becke (Ed.), Mindful change in times of permanent reorganization (pp. 33-48). Berlin: Springer. http://dx.doi.org/10.1007/978-3642-38694-7_3.

Rothwell, W. J., \& Kazanas, H. C. (2011). Mastering the instructional design process: a systematic approach. Hoboken: John Wiley \& Sons.

Rowden, R. W. (1996). Workplace learning: debating five critical questions of theory and practice. San Francisco: Jossey-Bass.

Saltman, D. C., O'Dea, N. A., Farmer, J., Veitch, C., Rosen, G., \& Kidd, M. R. (2007). Groups or teams in health care: finding the best fit. Journal of Evaluation in Clinical Practice, 13(1), 55-60. http://dx.doi.org/10.1111/j.1365-2753.2006.00649.x. PMid:17286724.

Santos, F. M. D. (2012). Análise de conteúdo: a visão de Laurence Bardin. Revista Eletrônica de Educação, 6(1), 383-387.

Schein, E. H. (2006). Organizational culture and leadership (Vol. 356). Hoboken: John Wiley \& Sons.

Senge, P. M. (1990). A quinta disciplina: arte, teoria e prática da organização de aprendizagem. Rio de Janeiro: Best Seller.

Shaw, M. E. (1971). Group dynamics: the psychology of small group behavior. New York: McGraw-Hill.

Stankosky, M. (Ed.). (2005). Creating the discipline of knowledge management: the latest in university research. London: Routledge.

Stiglitz, J. E., \& Greenwald, B. C. (2014). Creating a learning society: a new approach to growth, development, and social progress. New York: Columbia University Press.

Suh, A., Shin, K. S., Ahuja, M., \& Kim, M. S. (2011). The influence of virtuality on social networks within and across work groups: a multilevel approach. Journal of Management Information Systems, 28(1), 351-386. http://dx.doi.org/10.2753/MIS0742-1222280111.

Weisæth, L., Knudsen, Ø., Jr., \& Tønnessen, A. (2002). Technologi- cal disasters, crisis management and leadership stress. Journal of Hazardous Materials, 93(1), 33-45. http://dx.doi.org/10.1016/S0304-3894(02)00036-5. PMid:12062952. 
Collaborative learning in the production...

Wilkesmann, M., \& Wilkesmann, U. (2011). Knowledge transfer as interaction between experts and novices supported by technology. Vine, 41(2), 96-112. http://dx.doi.org/10.1108/03055721111134763.

Yukl, G. A., \& Becker, W. S. (2006). Effective empowerment in organizations. Organizational Management Journal, 3(3), 210-231. http://dx.doi.org/10.1057/omj.2006.20. 